\title{
Prevalence of Cardiovascular Risk Factors in Chronic Hemodialysis Patients at the University Hospital Center of Point G in Bamako, Mali
}

\author{
Seydou Sy ${ }^{1,2^{*}}$, Magara Samaké2,3, Moctar Coulibaly4, Massama Konaté2,5, Djénèba Diallo1,2, \\ Hamadoun Yattara1,2, Aboubacar Sidiki Fofana', Atabieme Kodio1, Modi Sidibé1, \\ Nouhoum Coulibaly', Alkaya Touré1, Djibril Sy,6, Moustapha Tangara',2, Saharé Fongoro ${ }^{1,2}$ \\ ${ }^{1}$ Nephrology and Haemodialysis Department of the CHU of Point G, Bamako, Mali \\ ${ }^{2}$ Faculty of Medicine, University of Bamako, Bamako, Mali \\ ${ }^{3}$ Nephrology Unit of the Fousseyni DAOU Hospital of Kayes, Kayes, Mali \\ ${ }^{4}$ Nephrology Unit of Mali GAVARDO Hospital, Bamako, Mali \\ ${ }^{5}$ Cardiology Department of Mali Hospital, Bamako, Mali \\ ${ }^{6}$ Internal Medicine Service at the University Hospital Center of Point G, Bamako, Mali \\ Email: *seydousy2002@yahoo.fr
}

How to cite this paper: Sy, S., Samaké, M., Coulibaly, M., Konaté, M., Diallo, D., Yattara, H., Fofana, A.S., Kodio, A., Sidibé, M., Coulibaly, N., Touré, A., Sy, D., Tangara, M. and Fongoro, S. (2020) Prevalence of Cardiovascular Risk Factors in Chronic Hemodialysis Patients at the University Hospital Center of Point G in Bamako, Mali. Open Journal of Nephrology, 10, 125-134. https://doi.org/10.4236/ojneph.2020.102013

Received: March 16, 2020

Accepted: May 25, 2020

Published: May 28, 2020

Copyright (๑) 2020 by author(s) and Scientific Research Publishing Inc. This work is licensed under the Creative Commons Attribution International License (CC BY 4.0).

http://creativecommons.org/licenses/by/4.0/

(c) (i) Open Access

\begin{abstract}
Introduction: A cardiovascular risk factor (FDRCV) is defined as a physiological, pathological or environmental attribute or characteristic that results in an increased likelihood of developing cardiovascular disease in the individual in whom it is detected. The objective of this study was to determine the prevalence of cardiovascular risk factors in hemodialysis patients on hemodialysis at the University Hospital of Point G. Patients and Methods: This was a cross-sectional descriptive study with prospective data collection from March 3, 2009 to March 5, 2010 (13 months). Included were all patients with end-stage renal disease (ESRD) receiving chronic hemodialysis in the Nephrology and Hemodialysis Department of the University Hospital of Point G during the study period. Results: Eighty-eight patients were enrolled. The $\mathrm{M} / \mathrm{F}$ sex ratio was 1.26 . The mean age was 41.32 years with extremes of 17 and 81 years. The classic cardiovascular risk factors in order of frequency were: hypertension $(90.9 \%)$, sedentary lifestyle (71.6\%), male sex (54.5\%), age $\geq 55$ years $(21.6 \%)$, obesity (13.6\%), diabetes $(8 \%)$, tobacco $(8 \%)$, alcohol (3.4\%). Cardiovascular risk factors related to CKD were: anemia (98.9\%), phosphocalcic disorders (85.2\%), arteriovenous fistula (AVF) (80\%), lipid abnormalities (36.5\%), hydrosodium inflation (29.5\%). Predominant cardiovascular complications were hypertensive heart disease (62.5\%), acute pulmonary oedema (APO) (50\%), rhythm disorders (23.9\%), coronary insufficiency $(18.2 \%)$. The mortality rate was $17 \%$. Conclusion: Cardiovascular risk
\end{abstract}


factors are frequent in chronic hemodialysis. They contribute to the excess mortality of these patients. Adequate management of these risk factors can slow down serious cardiovascular complications and reduce the risk of mortality in this fragile population.

\section{Keywords}

Cardiovascular Risk Factors, Haemodialysis, Mali

\section{Introduction}

A cardiovascular risk factor (FDRCV) is defined as a physiological, pathological or environmental attribute or characteristic that results in an increased likelihood of developing cardiovascular disease in the individual in whom it is detected [1]. FDRCV in hemodialysis patients are multiple and varied. They associate anemia, hydrosodium inflation, age, male sex, phosphocalcic disorders responsible for cardiac and vascular calcifications, lipid abnormalities, arteriovenous fistula (AVF), aluminium poisoning, but also hyperhomocysteinemia and coagulation disorders [1]. There are other so-called classic or global cardiovascular risk factors that patients with chronic renal failure share with the general population, mainly high blood pressure (hypertension), diabetes, alcohol, tobacco and a sedentary lifestyle. Cardiovascular diseases, whose prevalence in patients with end-stage renal disease (ESRD) is ten to thirty times higher than in the general population, are the leading cause of mortality [1]. Left ventricular hypertrophy (LVH), heart failure and atherosclerosis are responsible for cardiovascular morbidity and mortality [1]. As traditional factors are insufficient to explain their high cardiovascular morbidity and mortality, factors related to chronic kidney disease (CKD) and its treatment have been discussed. These include proteinuria, hydroelectrolyte disorders, anemia, increased lipoprotein (a) (Lp (a)) and homocysteine, microinflammatory status and increased thrombogenic factors [1]. Cardiovascular complications (heart failure, sudden death, myocardial infarction (MI), stroke, peripheral arteritis, mesenteric infarction) account for $50 \%$ of the causes of death in hemodialysis [2]. The association of these complications with anemia aggravates the already precarious functional status and quality of life of dialysis patients [3].

The objective of this study was to determine the prevalence of cardiovascular risk factors in hemodialysis patients on hemodialysis at the University Hospital Center (UHC) of Point G.

\section{Patients and Methods}

This was a cross-sectional descriptive study with prospective data collection, which was conducted over a 13-month period from 3 March 2009 to 5 March 2010. It involved chronic ESRD patients receiving chronic haemodialysis in the Nephrology and Haemodialysis Department of the UHC of Point G during the 
study period. Sociodemographic data (age, sex, occupation) and clinical data (history, cardiovascular risk factors) were collected by a comprehensive clinical examination of all patients. The cardiovascular risk factors studied were:

- Classic cardiovascular risk factors:

* High blood pressure (HBP): It is defined by a systolic blood pressure (SBP) greater than or equal to $140 \mathrm{mmHg}$ and/or a diastolic blood pressure (DBP) greater than or equal to $90 \mathrm{mmHg}$ at the doctor's office.

* Smoking: Defined as the chronic, addictive intoxication of the body by tobacco.

* Sedentary lifestyle: Sedentary lifestyle was defined as a lack of minimum physical activity that meets the needs of the human body, i.e. less than 150 minutes per week according to the ESC.

* Diabetes: According to the WHO, diabetes is defined by a polyuro-polydipsia syndrome and fasting plasma glucose $\geq 1.26 \mathrm{~g} / \mathrm{l}$ twice $(7 \mathrm{mmol} / \mathrm{l})$ or random blood glucose (venous plasma) $\geq 2 \mathrm{~g} / \mathrm{l}(11.1 \mathrm{mmol} / \mathrm{l})$ or blood glucose on venous plasma at the second hour of an orally induced hyperglycaemia $\geq 2 \mathrm{~g}$ /l (11.1 mmol/l).

* Alcoholism: It is a disease related to chronic abuse of alcoholic beverages, with alcohol dependence (more than 3 glasses in men and more than 2 glasses in women).

* Obesity: It is defined by a body mass index (BMI = Weight $(\mathrm{Kg}) /$ Height $\left.\left(\mathrm{m}^{2}\right)\right)>30 \mathrm{~kg} / \mathrm{m}^{2}$.

* Male sex:

* Age over 55 years:

- Cardiovascular risk factors related to CKD:

* Anemia: Defined as a decrease in circulating hemoglobin mass with hemoglobin levels $<13 \mathrm{~g} / \mathrm{dl}$ in men; $<12 \mathrm{~g} / \mathrm{dl}$ in women.

* Hydrosodic inflation: It is defined as excess weight compared to the ideal weight (dry weight).

* Phosphocalcic metabolism disorders: they classically associate hypocalcemia, hyperphosphatemia with a phosphocalcic product greater than $5.6 \mathrm{mmol}^{2} / \mathrm{l}^{2}$ and hyperparathyroidism $(\mathrm{PTH}>9$ times the upper limit of the laboratory standard).

* Lipid abnormalities: Associated with a decrease in HDL cholesterol $<0.6 \mathrm{~g} / \mathrm{L}$, an increase in LDL cholesterol $>1.6 \mathrm{~g} / \mathrm{L}$ and triglycerides $>1.5 \mathrm{~g} / \mathrm{L}$, a decrease in apolipoproteins AI and AII and an increase in apolipoprotein B and (a) (L(a)). apolipoproteins were not evaluated in our series.

* A.V.F.: An arteriovenous fistula is a surgically made neo-circulation characterized by low arterial resistance and increased venous return.

* Left ventricular hypertrophy was defined according to electrical (SOKOLOW Index $>35 \mathrm{~mm}$ ) and/or echocardiographic criteria (left ventricular mass in$\operatorname{dex} \geq 115 \mathrm{~g} / \mathrm{m}^{2}$ in men and $95 \mathrm{~g} / \mathrm{m}^{2}$ in women).

The complications sought were:

- Intra dialytic complications include: hypotension, hypertensive flare-up, 
convulsions, altered consciousness, cardiac arrest, fever, chills.

- Inter-dialytic complications include: hypertensive heart disease, coronary insufficiency, uremic pericarditis, stroke, acute lung edema, obliterative arterial disease of the lower limbs, septic shock, thrombophlebitis, pulmonary embolism, complications of V.A.F. (thrombosis, hematoma or aneurysmal rupture).

The duration of illness (ESRD/CAD), radiological investigations, few more bio physiological parameters also added to identify the risk.

Each patient in the series was given an individual follow-up sheet with systematic recording of sociodemographic, clinical and para-clinical data.

Data entry and analysis was performed on SPSS12.0. The statistical test used was Pearson Chi-square with $\mathrm{p}<0.05$ as a significant value.

Verbal informed consent was obtained from patients after explanation of the purpose of the study.

\section{Results}

We rounded up 88 patients. There were 49 males (55.7\%) and 39 females (44.3\%) with an M/F sex ratio of 1.26 . The mean age was 41.32 years with extremes of 17 and 81 years. Civil servants accounted for 30.7\%. School-age haemodialysis patients (47) accounted for 53.40\%. Married people accounted for $79.5 \%$. Eighty (80) patients or $90.9 \%$ had a personal history of hypertension. Inter-dialysis weight gain was on average $2.26 \mathrm{~kg}$ with extremes of 1 and $4 \mathrm{~kg}$. The average dry weight was $62.73 \mathrm{~kg}$ with extremes of 37 and $99 \mathrm{~kg}$. The classic cardiovascular risk factors in order of frequency were hypertension (90.9\%), sedentary lifestyle (71.6\%), male sex (54.5\%), age $\geq 55$ years (21.6), obesity (13.6\%), diabetes (8\%), tobacco (8\%), alcohol (3.4\%) (Table 1). Cardiovascular risk factors related or specific to CKD were anemia (98.9\%), phosphocalcic disorders (85.2\%), AVF (80\%), lipid abnormalities (36.5\%), hydrosodium inflation (29.5\%) (Table 2). The main intradialytic complications observed were: headache 58 cases (65.9\%), fever 55 cases (62.5\%), chills 50 cases (56.8\%), hypertensive attacks 47 cases $(53.4 \%)$, chest pain 42 cases (47.7\%), vomiting 39 cases (44.3\%), hypotension 37 cases (42\%) (Table 3 ). The predominant interdialytic complications were: hypertensive heart disease 55 cases (62.5\%), acute lung edema44 cases (50\%), rhythm disorders 21 cases $(23.9 \%)$, coronary insufficiency 16 cases (18.2\%), haemorrhages (epistaxis 12 cases (13.6\%), haematemesis 6 cases $(6.8 \%)$, rectorragy 1 case (1.1\%), haemoptysis 1 case (1.1\%) (Table 4$)$. The mortality rate was $17 \%$. The causes of death were sudden death 9 cases, septic shock 2 cases, hemorrhagic shock 2 cases, acute lung edema 1 case and stroke 1 case. Physical inactivity was age-related $(\mathrm{P}=0.048)$. Smoking was correlated with male sex $(P=0.039)$. Diabetes was a risk factor for lower limb arterial occlusive disease (LAOD) $(\mathrm{P}=0.0001)$. Anemia was a risk factor for AVF thrombosis $(\mathrm{P}=0.021)$ and pulmonary embolism $(\mathrm{P}=0.010)$. Lipid abnormalities $(\mathrm{P}=$ $0.049)$ and male sex $(P=0.047)$ were risk factors for hypertensive cardiomyopathy. 
Table 1. Distribution of patients according to classic cardiovascular risk factors.

\begin{tabular}{ccc}
\hline Classic risk factors & Staff & Percentage \\
\hline HTA & 80 & 90.9 \\
Diabetes & 7 & 8 \\
Tobacco & 7 & 8 \\
Alcohol & 3 & 3.4 \\
Sédentarité & 63 & 71.6 \\
Obesity & 12 & 13.6 \\
Age $>$ or $=55$ years old & 19 & 21.6 \\
Male sex & 49 & 54.5 \\
\hline
\end{tabular}

HTA was the most common classical risk factor.

Table 2. Patient distribution by cardiovascular risk factors related CKD.

\begin{tabular}{ccc}
\hline Risk factors specific to IRC & Staff & Percentage \\
\hline Anemia & $\mathbf{8 7}$ & $\mathbf{9 8 . 9}$ \\
Hydro-sodium inflation & 26 & 29.5 \\
Phosphocalcic disorders & 75 & 85.2 \\
Lipid abnormalities & 32 & 36.4 \\
AVF & 71 & 80.7 \\
\hline
\end{tabular}

Anemia was found in $98.9 \%$ of patients.

Table 3. Distribution of patients according to observed intradialytic complications.

\begin{tabular}{|c|c|c|}
\hline Intra dialytic complications & Staff & Percentage \\
\hline Headache & 58 & 65.9 \\
\hline Fever & 55 & 62.5 \\
\hline Shivers & 50 & 56.8 \\
\hline Hypertensive surges & 47 & 53.4 \\
\hline Chest pain & 42 & 47.7 \\
\hline Vomiting & 39 & 44.3 \\
\hline Low blood pressure & 37 & 42 \\
\hline Abdominal pain & 25 & 28.4 \\
\hline Nausea & 23 & 26.1 \\
\hline Cramps & 11 & 12.5 \\
\hline Convulsions & 4 & 4.5 \\
\hline Disorders of consciousness & 4 & 4.5 \\
\hline Acute Hemolysis & 1 & 1.1 \\
\hline
\end{tabular}

Headache, fever and chills were the most common symptoms encountered in per dialysis. 
Table 4. Distribution of patients according to observed interdialytic complications.

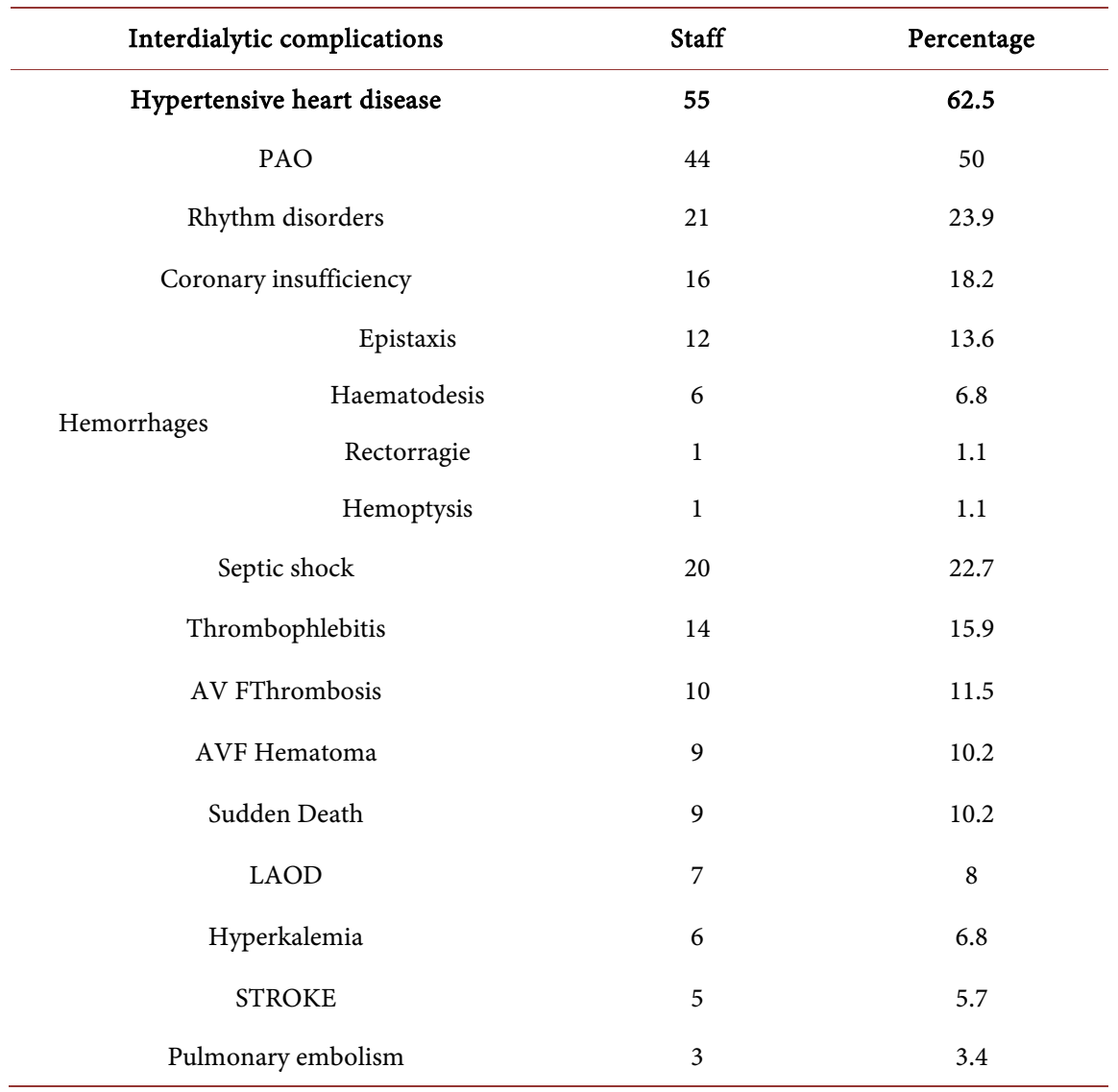

Interdialytic complications were dominated by hypertensive heart disease.

AVF was a risk factor for cardiac arrest $(\mathrm{P}=0.001)$ and rhythm disorders $(\mathrm{P}=$ 0.029).

Vascular nephropathy was the leading cause of chronic end-stage renal disease at $59.1 \%$. Hypertensive retinopathy according to KIRKENDAL $(n=86)$ was found in 44 cases $(51.16 \%)$, diabetic retinopathy in 2 cases $(2.32 \%)$, and mixed diabetic and hypertensive retinopathy in 3 cases $(3.5 \%)$.

A chest $\mathrm{x}$-ray of the face showed cardiomegaly in $55.68 \%$ of cases. The electrocardiogram showed LVH according to SOKOLOW 43 cases (48.9\%), repolarization disorders 12 cases (13.6\%), conduction disorders 6 cases $(6.8 \%)$, excitability disorders 2 cases (2.3\%), signs of necrosis 2 cases $(2.3 \%)$ and 1 case of left ventricular hypertrophy associated with right atrial hypertrophy (Table 5). Cardiac ultrasonography showed LVH in $55.7 \%$ of cases (septal: $15.9 \%$, parietal: $2.3 \%$ and septo-parietal: $37.5 \%$ ), relaxation disorders in $22.5 \%$, dilatation of the cavity in $21.5 \%$, valvular lesions in $18.2 \%$ and pericardial effusion in $18.2 \%$ of cases. Arteriovenous echodoppler was pathological in 36.62\% (atherosclerosis: 13 cases $(18.31 \%)$, renal artery stenosis: 7 cases (9.86\%), malformation: 4 cases (5.63\%), thrombophlebitis: 2 cases $(2.82 \%))$.

Calcium channel blockers and ACE inhibitors were most often used for the control of hypertension in $85.2 \%$ and $45.5 \%$ respectively. 
Table 5. Distribution of patients according to the electrical signs found.

\begin{tabular}{ccc}
\hline ECG & Staff & Percentage \\
\hline Normal & 38 & 43.2 \\
Repolarization disorders & 12 & 13.6 \\
Conduction disorders & 6 & 6.8 \\
Excitability disorders & 2 & 2.3 \\
Signs of necrosis & 2 & 2.3 \\
LVH & 43 & 48.9 \\
LVH + Right atrial hypertrophy (RAH) & 1 & 1.1 \\
\hline
\end{tabular}

Forty-eight point nine percent of the patients had left ventricular hypertrophy.

\section{Discussion}

Limitations of the study: Patients whose records were incomplete or unusable due to a lack of financial means to perform radiological and biological explorations, and the lack of consent of some, contributed to the reduction of our sample size.

Our study involved 88 chronic hemodialysis patients. The mean age was 41.32 years with extremes of 17 and 81 years. Fongoro S [4] reported a mean age of 38 years. In contrast, Yattara H [5], and Cissé MM [6] reported an average age of 48 and 52 . The sample was composed of $55.7 \%$ men and $44.3 \%$ women, with a sex ratio of 1.26. The sample was also made up of women and men. This male predominance is in agreement with other authors [4] [5] [6] versus a female predominance in Nouakchott reported by Eba A [3]. This can be explained by the fact that the male sex is a risk factor for CKD according to BLACHER J. in France [7]. The prevalence of cardiovascular disease is 10 to 30 times higher in these patients than in the general population [1] [8]. It's an increased prevalence of traditional risk factors but also to risk factors related to End Stage Renal Diseases [9]. In our study, the classic cardiovascular risk factors were: hypertension (90.9\%), physical inactivity (71.6\%), male sex (54.5\%), age $\geq 55$ years (21.6), obesity (13.6\%), diabetes (8\%), tobacco (8\%), alcohol (3.4\%). In the literature, the frequency of hypertension varied between $67 \%$ and $95 \%$ [4] [5] [9] [10]. In the CHOICE study (choices for healthy outcomes in caring for end-stage renal disease) aimed at specifying the characteristics of the database of patients starting dialysis, prevalences of $54 \%$ and $96 \%$ were reported for diabetes and hypertension respectively [11]. Risk factors related to CKD found in our study were anemia (98.9\%), phosphocalcic disorders (85.2\%), AVF (80\%), lipid abnormalities (36.5\%), and hydrosodium inflation (29.5\%). In the study of Fongoro S. study [4], the cardiovascular risk factors found were anemia in 41 cases $(97.62 \%)$, hypertension in 40 cases (95.24\%), sodium retention in 52.40\%, AVF (30.95\%) and hyperparathyroidism in 9 patients $(4.76 \%)$. Another study carried out in the same department in 2017 [5] found anaemia (95.1\%), phosphocalcic disorders (69\%), male sex (60.2\%), hypertension (59\%) and smoking (43.3\%). Anemia was 
almost constant in all patients. This could be explained not only by the deficit of erythropoietin synthesis, reduced erythrocyte half-life, deficiency states and bleeding during CKI [1] [8] [12] [13] but also by the non-availability of erythropoietin (EPO) in Mali at the time of our study. In the Kitoune study [10], the cardiovascular risk factors were hypertension 35 cases (92.1\%), dyslipidemia (76.31\%), AVF (65.78\%), anemia with $\mathrm{Hb}<10 \mathrm{~g} / \mathrm{dl}(36.84 \%)$, diabetes (23.68\%). Cardiomegaly was found in 55.68\% of our patients. Fongoro S [4] and Cissé MM [6] found $76.20 \%$ and $63.16 \%$ respectively) which could be explained by the persistence of hypertension, anaemia, hydrosodic inflation and AVF. Electric LVH was found in $48.9 \%$. Cardiac ultrasonography showed LVH in $55.7 \%$ of cases (septal: $15.9 \%$, parietal: $2.3 \%$ and septo-parietal: $37.5 \%$ ). In the literature, Fongoro [4], Kitoune [11], and Cissé MM [6] found electrical VGH in $69.04 \%$, $63.15 \%, 71.05 \%$ respectively. This can again be explained by the role of hypertension, anaemia, hydrosodic inflation and FAV in its occurrence. The predominant cardiovascular complications in our study were hypertensive heart disease (62.5\%), acute pulmonary edema (APO) (50\%), rhythm disorders (23.9\%), and coronary artery disease (18.2\%). These complications have been reported by some authors. In Fongoro's study [4], these complications were dominated by APO (40.5\%), congestive heart failure (21.40\%), coronary artery disease (23.80\%), pericarditis $(21.40 \%)$ and rhythm disorders. Cissé [6] reported coronary heart disease $(34.21 \%)$, congestive heart failure (18.42\%), vascular calcifications and hemorrhagic strokes in 5.78 and $5.26 \%$ of cases respectively.

Echodoppler of large trunks was pathological in 36.62\% (Atherosclerosis: 13 cases (18.31\%), Renal stenosis: 7 cases (9.86\%), malformation: 4 cases $(5.63 \%)$, thrombophlebitis: 2 cases $(2.82 \%)$ ). This can be explained by lipid abnormalities and hemostasis disorders observed during CKD [7]. Multivariate analysis showed that all classic FDRCVs were present in the $41-50$ and $61-70$ age groups. There was an association between sedentary lifestyle and age $(\mathrm{P}=0.048)$. In contrast, all of the FDRCVs specific to the related to chronic end-stage renal disease (ESRD) were present in all age groups.

Males not only had all the classic FDRCVs, but also had a relationship with smoking $(\mathrm{P}=0.039)$. In contrast, all of the CKD-specific FDRCVs were present in both sexes. Obesity was a risk factor for thrombophlebitis $(p=0.028)$. Diabetes was a risk factor for lower limb arterial occlusive disease (LAOD) $(\mathrm{P}=$ $0.0001)$. Anemia was a risk factor for AVF thrombosis $(\mathrm{P}=0.021)$ and pulmonary embolism $(P=0.010)$. Lipid abnormalities $(P=0.049)$ and male sex $(P=$ $0.047)$ were risk factors for hypertensive cardiomyopathy. AVF was a risk factor for cardiac arrest $(P=0.001)$ and rhythm disorders $(P=0.029)$. Cardiac arrest was not observed with intradialysis. Pericarditis and mesenteric infarction were not observed during interdialysis follow-up, but hypertensive heart disease (62.5\%) followed by PAO (50\%) in agreement with the other authors [4]. This can be explained by the high frequency of hypertension (90.9\%) in our series and the failure to comply strictly with the prescribed hygieno-dietary measures. The 
mortality rate was $17 \%, 60 \%$ of which was due to cardiovascular causes. The mortality rate was $26.6 \%$ in Kitoune [10], 29\% in Cissé [6] and 36\% in Kane A. [14]. All these authors reported the cardiovascular predominance of the causes of death as reported in the literature [1] [8].

\section{Conclusion}

Cardiovascular risk factors are common in chronic hemodialysis. They contribute to the excess mortality of these patients. Proper management of these risk factors can slow down serious cardiovascular complications and reduce the risk of mortality in this fragile population.

\section{Conflicts of Interest}

None.

\section{References}

[1] Man, N.K., et al. (2010) Problèmes cardio-vasculaires, in Hémodialyse de suppléance. Flammarion. Ed., PubMed, Google Scholar.

[2] Meier, P., Saudan, P., Burnier, M. and Martin, P.Y. (2003) Co-Morbidity and Cardiovascular Risk Factors Associated with Chronic Renal Failure. https://serval.unil.ch/fr/notice/serval:BIB_C8EA7F02157C

[3] Eba, A., Aghrabatt, M.S., Moustapha, S.M., et al. (2006) Cardiovascular Complications in Chronic Renal Failure Patients on Dialysis. Cardiologie Tropicale, 32, 19-23.

[4] Fongoro, S., Maïga, M.K. and Ben Aboubacar, D. (2003) Cardiac Complications in Chronic Renal Failure in the Nephrology and Haemodialysis Department of the National Hospital of Point G. Mali Médical, 18, 12-16.

[5] Yattara, H., Sidibé, S., Diallo, D., Koungoulba, M., Djiguiba, K., Tangara, M., Fofana, A.S., Coulibaly, S., Coulibaly, N., Coulibaly, M. and Fongoro, S. (2018) Prevalence of Echocardiographic Abnormalities in Hemodialysis Patients at CHU Point G. Mali Medical, 33, 19-22.

[6] Moustapha, C.M., Tall, L.A., Maria, F., et al. (2016) Evaluation of Cardiac Complications in Chronic Haemodialysis Patients in Dakar. Pan African Medical Journal, 23, 43. https://doi.org/10.11604/pamj.2016.23.43.7227

[7] Blacher, J. (2009) Cardiovascular Epidemiology and Central Pressure: From Concept to Clinical Application. Edition Elsevier-Masson SAS, Paris.

[8] Madore, F. (2004) Vascular Risk Factors and Renal Failure. Medicine/Science, 20, 1100-1103.

[9] Berrachdi, W., Batouche, D.D., Sadaoui, L. and Benatta, N.F. (2017) Prevalence of Cardiovascular Complications in Chronic Renal Failure Patients on Dialysis in Oran. Nephrology \& Therapeutics, 13, 389-390. https://doi.org/10.1016/j.nephro.2017.08.287

[10] Chawki, K. and Idir, N. (2017) Cardiovascular Complications in Hemodialysis-Dependent Renal Failure [Memory]. Abderrahmane Mira University of Bejaia, Algeria.

[11] Longenecker, J., Coresh, J., Powe, N., et al. (2002) Traditional Cardiovascular Disease Risk Factors in Dialysis Patients Compared with the General Population: The 
Choice Study. Journal of the American Society of Nephrology, 13, 1918-1927. https://doi.org/10.1097/01.ASN.0000019641.41496.1E

[12] Berland, Y. and Dussol, B. (2003) Nephrology for Intern Volume 4. Faculté de Médecine de Marseille. Edition Elsevier, Paris.

[13] Thomas, D., Jean, I.A., Bertrand, E., Valeria, B., Annick, C. and Christian, C. (1994) Cardiology, French-Speaking Universities. Edition Ellipses, Paris.

[14] Kane, A., Bidani, A., Diouf, B., et al. (2000) Cardiovascular Abnormalities in Chronic Hemodialysis. Tropical Cardiology, 26, 51-55. 